\title{
Effect of Green Tea on the Formation of Nitrosamines, and Cancer Mortality
}

\author{
Shuichi Masuda, ${ }^{*, a}$ Shoko Uchida,${ }^{a}$ Yumeko Terashima, ${ }^{a}$ Hiroko Kuramoto ${ }^{a}$ Mika Serizawa, ${ }^{a}$ \\ Yuya Deguchi, ${ }^{a}$ Kazuhiro Yanai, ${ }^{a}$ Chitose Sugiyama, $^{b}$ Itaro Oguni, ${ }^{b}$ and Naohide Kinae ${ }^{a}$ \\ ${ }^{a}$ Graduate School of Nutritional and Environmental Sciences, COE Program in the 21 st Century, University of Shizuoka, 52-1 Yada, \\ Suruga-ku, Shizuoka 422-8526, Japan and ${ }^{b}$ School of Health Promotional Science, Hamamatsu University, 230, Toda-cho, Hamamatsu, \\ Shizuoka 431-2102, Japan
}

(Received October 30, 2005; Accepted February 1, 2006)

\begin{abstract}
The effects of repeatedly brewed green tea infusion on the formation of nitrosamine in vitro and in vivo, and on cancer mortality were examined. The first and second brews of green tea infusion inhibited the formation of nitrosomorpholine in the presence of morpholine and nitrite (nitrosation of morpholine), but the third to eighth brews accelerated it. The green tea infusion brewed from $5 \mathrm{~g}$ of leaves in $200 \mathrm{ml}$ hot water (strong tea infusion) inhibited the nitrosation of morpholine, but that brewed from $2.5 \mathrm{~g}$ or less (weak tea infusion) promoted the nitrosation. The brewed green tea infusion that inhibited nitrosation of morpholine contained catechins at a high concentration, and that that promoted nitrosation contained catechins at a low concentration. The effects of green tea administered to Wistar male rats and that consumed by humans on the formation of nitrosamines were also examined. In both rats and humans, nitrosamine formation was inhibited by strong green tea extract but was increased by weak green tea extract. The concentration of catechins in the green tea infusion brewed by the general households in tea-producing areas was significantly higher than that brewed in non-producing areas. We examined the relationship between the concentration of catechins in green tea infusion brewed in different areas and the standardized mortality ratio (SMR) of cancer in respective areas, and found that the catechin concentration in green tea infusion correlated inversely and significantly with the SMR of cancer in that area. We concluded that strong green tea might inhibit the formation of nitrosamines and decrease the risk of carcinogenesis.
\end{abstract}

Key words — green tea, catechin, nitrosamine, carcinogenicity, standard mortality ratio

\section{INTRODUCTION}

We are exposed to many kinds of chemicals that are present in the air, water, soil and food. Some of them have mutagenic and carcinogenic activities on bacteria and mammals. ${ }^{1,2}$ Among them, nitrosamines are well known as strong mutagens/carcinogens, and as etiological factors of gastric cancer. ${ }^{3,4)}$ Nitrosamines are formed from secondary amines and nitrite under gastric $\mathrm{pH}$ conditions. They are present in foods eaten every day, such as fish and meat, thus it is important to know how to protect carcinogenesis induced by nitrosamines.

Green tea and its components have antioxidative, ${ }^{5)}$ radical scavenging, ${ }^{6)}$ antibacterial,${ }^{7)}$ antimu-

*To whom correspondence should be addressed: Graduate School of Nutritional and Environmental Sciences, University of Shizuoka, 52-1 Yada, Suruga-ku, Shizuoka 422-8526, Japan. Tel.: +81-54-264-5526; Fax: +81-54-264-5528; E-mail: masudas@u-shizuoka-ken.ac.jp tagenic $^{8)}$ and anticarcinogenic ${ }^{9)}$ activities in vivo and in vitro. Brewed green tea infusion has been confirmed to have preventive effects on the development of induced cancers in animals. Catechins, such as (-)epigallocatechin gallate, are main constituents of green tea polyphenol, and have been shown to inhibit the promotion of induced carcinogenesis. ${ }^{10}$ Green tea might show preventive effect on life-style related diseases such as diabetes and arteriosclerosis. ${ }^{11,12)}$ Furthermore, green tea and catechins reportedly inhibited the formation and mutagenicity of nitrosamines. Nakamura and Kawabata described the effect of brewed green tea on the formation of nitrosodimethylamine in the reaction mixtures of dimethylamine and nitrite under acidic conditions. ${ }^{13)}$ Tanaka et al. also reported the inhibitory potency of catechins in green tea extract on the nitrosation of dimethylamine, morpholine and methylaniline. ${ }^{14)}$ However, they did not examine the inhibitory effect of green tea infusion brewed by the general method on the formation of nitrosamines. Therefore, it is 
important to study the effect of routinely brewed green tea infusion on the nitrosation of secondary amines.

Stomach cancer is the No. 2 cause of cancer deaths in the world, and its incidence and mortality in Japan are higher than in any other country in the world. ${ }^{15)}$ There are some epidemiological reports that the consumption of green tea infusion reduced the risk of gastric cancer in case-control studies. ${ }^{16-21)} \mathrm{In}$ contrast, some researchers reported that the consumption of green tea was not associated with the reduction of gastric cancer using recent prospective studies. ${ }^{22-25)}$ In these reports that described the inhibitory effects or non-effects of green tea against cancer death, the relationship between the numbers of cups of green tea consumed and cancer death was examined, but the concentrations of catechins in the brewed tea infusion were not determined.

In this study, we examined the inhibitory effect of green tea on the formation of nitrosamines in vitro and in vivo to clarify the optimal intake of green tea against carcinogenesis by nitrosamines. Furthermore, we determined the catechins concentrations in green tea infusion brewed by the general household in green tea producing and non-producing areas in Japan. Furthermore, we studied the relationship between catechins concentrations in a cup of brewed green tea infusion and standard mortality ratio (SMR) of stomach, lung and colon cancers in 14 areas in Japan.

\section{MATERIALS AND METHODS}

Chemicals — Sodium nitrite, ammonium sulfamate, sodium citrate, citric acid monohydrate, dimethylsulfoxide (DMSO), (-)-epicatechin, (-)epigallocatechin, (-)-epicatechin gallate, (-)epigallocatechin gallate, (+)-catechin, resorcinol, phloroglucinol, dehydrate, catechol, pyrogallol, methyl gallate, gallic acid, phenol, hydroquinone, anhydrous sodium sulfate and o-tolunitrile were obtained from Wako Pure Chemical Industries, Ltd. (Osaka, Japan). Morpholine, nitrosomorpholine, methanol, dichloromethane and hydrochloric acid were bought from Kanto Kagaku Co., Ltd. (Tokyo, Japan).

Green Tea Brewing Method — Green tea leaves $(5.0 \mathrm{~g})$ was brewed by hot water $\left(80^{\circ} \mathrm{C}, 200 \mathrm{ml}\right)$ and stood for $1 \mathrm{~min}$. The method was repeated 8 times without changing tea leaves to collect each extract, as a result, we examined eight extracts. In an addi- tional experiment, we brewed tea leaves once using a different amount of tea leaves $(0.1,0.5,1.0,2.5$, $5.0 \mathrm{~g}$ ). Each extract was used as sample.

Nitrosation of Morpholine in Vitro - We performed and improved this method according to methods used by Groenen et al. ${ }^{26)}$ and Pignatelli et al. ${ }^{27)}$ Ten milliliters of each brewed green tea infusion was adjusted at $\mathrm{pH} 3.0$ by addition of hydrochloric acid. Sodium nitrite and morpholine were added to each extract to make a final concentration of 7.25 and $2 \mathrm{mM}$, respectively. For determining the inhibitory effect of chemicals, such as (+)-catechin, resorcinol, phloroglucinol, catechol, pyrogallol, gallic acid, methyl gallate, phenol and hydroquinone, on the nitrosomorpholine formation, each chemical was dissolved in distilled water or DMSO, and added to $10 \mathrm{ml}$ of $200 \mathrm{mM}$ citrate buffer (pH 3.0) containing $7.25 \mathrm{mM}$ sodium nitrite and $2 \mathrm{mM}$ morpholine. The mixture was incubated at $37^{\circ} \mathrm{C}$ for $30 \mathrm{~min}$, and the reaction was stopped by addition of $7.25 \mathrm{mM}$ of ammonium sulfamate. Each reaction mixture was filtrated by DISMIC-13HP $(0.45 \mu \mathrm{m}$, Toyo Roshi Kaisha, Ltd., Tokyo, Japan), and the concentrations of nitrosomorpholine formed in the reaction mixtures were analyzed by high performance liquid chromatography (HPLC).

HPLC Analysis of Nitrosomorpholine — The concentration of nitrosomorpholine in the reaction mixtures was determined by HPLC using Shimadzu LC-6A series system (Shimadzu, Kyoto, Japan) equipped with a UV detector (SPD-6A, Shimadzu) set at a UV wavelength of $239 \mathrm{~nm}$. A HiQ sil C18V column (4.6 i.d., $250 \mathrm{~mm}$ in length: KYATECH, New York, U.S.A.) was used. For detection of nitrosomorpholine, 5\% methanol in purified water was used as the mobile phase. The flow rate was $1.0 \mathrm{ml} /$ min. The temperature of the column oven was $40^{\circ} \mathrm{C}$. Determination of Catechin Concentration in Brewed Tea Infusion —_ Each brewed tea infusion was diluted to $10 \%$ by mobile phase, whose composition was $0.5 \%$ phosphoric acid and methanol $(82: 18)$. The diluted solutions were filtered through DISMIC-13HP $(0.45 \mu \mathrm{m}$, Toyo Roshi Kaisha, Ltd.), and then filtrates were applied to HPLC analysis. HPLC apparatus was composed with Shimadzu LC-6A series system (Shimadzu) equipped with an electron capture detector (ECD) (NANOSPACE SI-1/2005, Shiseido, Tokyo, Japan) set at a voltage of $600 \mathrm{mV}$. CAPCELL PAK C18 UG120 column (4.6 i.d., $150 \mathrm{~mm}$ in length: Shiseido) was used. For detection of catechins, the mobile phase composition was isocratic. The flow rate was 
$0.8 \mathrm{ml} / \mathrm{min}$. The temperature of the column oven was $40^{\circ} \mathrm{C}$.

Nitrosation of Morpholine in Rat — We performed and improved this method according to methods used by Pignatelli et al. ${ }^{27)}$ Six-week-old Wistar male rats (Japan SLC, Hamamatsu, Japan) were housed in an air-conditioned room and given $\mathrm{CE}-2$ commercial food pellets (Crea Japan, Tokyo, Japan) ad libitum. Five rats were assigned to each experimental group. They were fasted for $24 \mathrm{hr}$, and then freeze-dried green tea extract was administered by gastric intubation at a dose of $0,1.0,2.0,4.0,10$ or $20 \mathrm{mg} / \mathrm{kg}$ body weight. At the same time, the water solution of sodium nitrite and morpholine were administered in a similar way at a dose of 40 and $20 \mu \mathrm{mol} / \mathrm{kg}$ body weight, respectively. At $30 \mathrm{~min}$ after administration, the stomach was cut out from each rat. Stomach was homogenized with $25 \mathrm{ml}$ water, and centrifuged (3000 g, $10 \mathrm{~min})$. The supernatant was treated with $50 \mathrm{ml}$ of dichloromethane three times. Combined extracts were dehydrated through anhydrous sodium sulfate and concentrated with a rotary evaporator under nitrogen to a final volume of $0.5 \mathrm{ml}$. The extracts were analyzed for nitrosomorpholine by GC/MS. $o$-Tolunitrile was used as an internal standard. The experimental procedures used in this study met the guidelines of the Animal Care and Use Committee of the University of Shizuoka.

\section{The Formation of Nitrosodimethylamine in the}

Human Body — Twelve healthy non-smoking volunteers (six males and six females) participated in this experiment. The experiment was approved by medical ethical committee of the University of Shizuoka. The volunteers signed an informed consent, and answered to a questionnaire on food consumption and lifestyle habits. The participants had not taken either medicine or vitamin preparations prior to or during the study. The mean weight of the subjects ( \pm S.D.) was $60.9 \pm 15.5 \mathrm{~kg}$ (range $42-$ $96 \mathrm{~kg}$ ) and mean age was $28.8 \pm 8.8$ years (range 22-53 years). The study period was 4 days; the first three days of the study period were control days and the last day was the experimental day. During the control days, the volunteers refrained from consumption of food items containing high nitrosodimethylamine, nitrate, nitrite, amines, sulfur compounds, ascorbic acid and phenolic compounds containing food items in order to determine the background level of urinary excretion of nitrosodimethylamine. The experimental meal used in this experiment consisted of cooked rice $(180 \mathrm{~g})$, boiled marsh grass (80 g), one egg, french fries (50 g) and dried squid (50 g). The amounts of the precursors of nitrosodimethylamie in foodstuffs were $360 \mathrm{mg}$ nitrate contained in $80 \mathrm{~g}$ boiled marsh grass, and $91.4 \mathrm{mg}$ dimethylamine in $50 \mathrm{~g}$ dried squid. All volunteers were participated in four experimental groups, such as control, group A, B and C. Group A; did not drink green tea infusion, Group B; consumed green tea infusion at a low concentration (30 mg catechins/200 ml), Group $\mathrm{C}$; consumed green tea infusion at a high concentration $(300 \mathrm{mg}$ catechins $/ 200 \mathrm{ml}$ ). The urine samples were collected for $18 \mathrm{hr}$ after the experimental diets were consumed (18 hr urine). Each sample was extracted with three $500 \mathrm{ml}$ dichloromethane. The combined extracts were dried through anhydrous sodium sulfate, concentrated by rotary evaporator, and then concentrated under nitrogen to a final volume of $0.5 \mathrm{ml}$. The extracts were analyzed for nitrosodimethylamine concentration by GC/MS. $o$-Tolunitrile was used as an internal standard.

GC/MS Analysis of Nitrosamines - Nitrosomorpholine and nitrosodimethlyamine in dichloromethane extracts were analyzed with a HP 6890 GC-HP 5972A MS system. The capillary column was a TC-WAX $(30 \mathrm{~m} \times 0.25 \mathrm{~mm} \times 0.25 \mu \mathrm{m}, \mathrm{GL}$ Science Inc., Tokyo, Japan). Helium was used as a carrier gas at a flow rate of $1.0 \mathrm{ml} / \mathrm{min}$. The oven temperature was increased from 50 to $150^{\circ} \mathrm{C}$ at a rate of $5^{\circ} \mathrm{C} / \mathrm{min}$, and then kept $150^{\circ} \mathrm{C}$ for $10 \mathrm{~min}$. The temperature of the injector and GC-MS transfer line was kept at $220^{\circ} \mathrm{C}$. The MS detector was run in electron impact ionization mode, and the electron energy was $70 \mathrm{eV}$. Nitrosomorpholine and nitrosodimethylamine were quantified in selected-ion monitoring mode using the molecular ions 116 and 74 , respectively.

Sampling Green Tea Infusion Brewed by General Households in Different Areas and the SMR of Cancer in Respective Areas — We collected green tea infusion brewed by general households in 14 areas including green tea producing and non-producing areas in Japan. We defined the areas producing $500 \mathrm{t}$ and more green tea as tea-producing areas, and those producing less than $500 \mathrm{t}$ as non-producing areas. Green tea infusion was brewed by the usual method, in which hot water was poured on green tea leaves in teapot under traditional conditions. Green tea infusion was put into containers by each family in areas. The brewed tea infusion was transported to our laboratory under refrigeration. Fifteen to 20 tea infusion samples were collected from each area. 

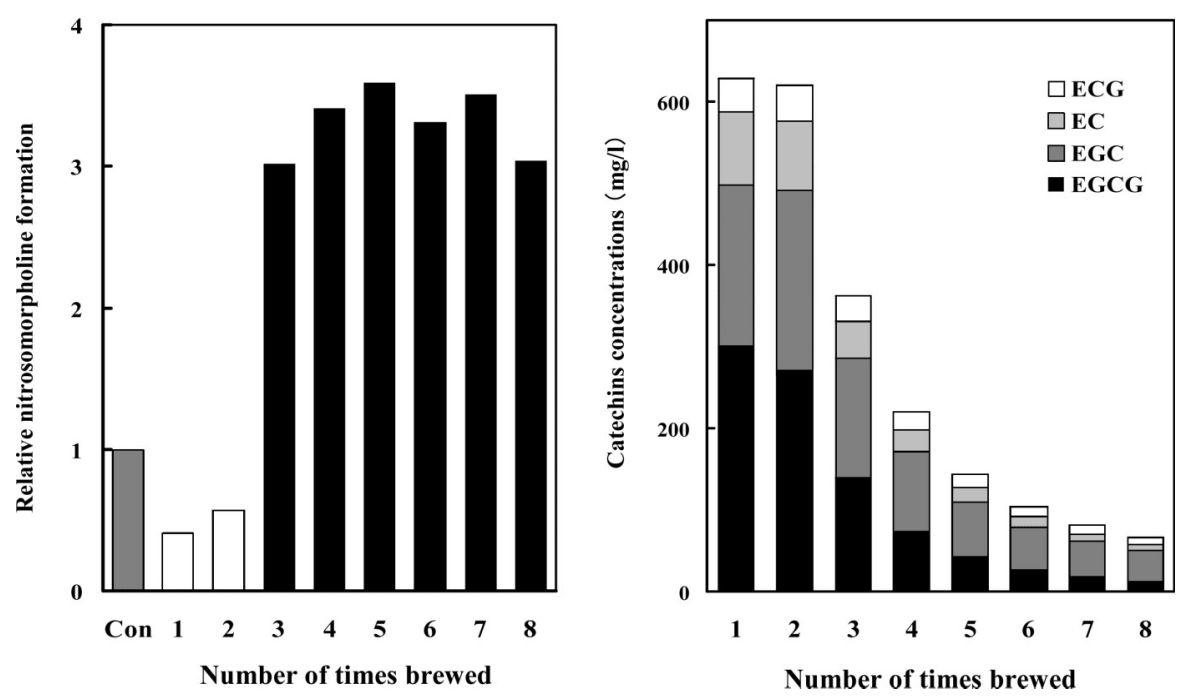

Fig. 1. Effect of Green Tea Brewed Repeatedly on the Formation of Nitrosomorpholine in the Presence of Morpholine and Nitrite

Until the determination of catechins concentration using HPLC apparatus, samples were kept cold. The SMR of cancer in each area was obtained from the Japan Health Promotion \& Fitness Foundation.

Statistics — A $t$-test was used to evaluate the significance of the differences in the production of nitrosoamines between experimental groups. The significance of the relationship between SMR of cancer and the concentration of catechins in each cup of brewed green tea infusion was evaluated by regression analysis. In these tests, $p$-values lower than 0.01 or 0.05 were considered to be statistically significant.

\section{RESULTS AND DISCUSSION}

We examined the effect of green tea infusion brewed repeatedly using the same leaves on the formation of nitrosomorpholine from morpholine and nitrite under acidic conditions ( $\mathrm{pH} 3.0$ ) in vitro. Figure 1 shows the relative amounts of nitrosomorpholine formed in the green tea infusion after repeated brewing. The first and second brews of green tea infusion suppressed the formation of nitrosomorpholine from morpholine and nitrite to 0.4 and 0.6 -fold of that in the absence of green tea infusion, respectively (Fig. 1). However, the third to eighth brews accelerated the nitrosation of morpholine about 3-fold (Fig. 1). The concentrations of (-)epicatechin, (-)-epigallocatechinm (-)-epicatechin gallate and (-)-epigallocatechin gallate, in each brew were determined by HPLC. In the first and second brews concentrations of catechins were 628 and $620 \mathrm{mg} / \mathrm{l}$, respectively. In the third to eighth brews, the concentration of catechins was $363,221,145$, 110,82 and $68 \mathrm{mg} / \mathrm{l}$ in this order. With repeated brewing the concentration of catechins in the brewed green tea infusion decreased (Fig. 1).

We examined the effect of the amounts of green tea leaves used for brewing on the formation of nitrosomorpholine from morpholine and nitrite in the brewed tea infusion. Green tea infusion brewed from $5 \mathrm{~g}$ leaves per $200 \mathrm{ml}$ hot water (strong tea infusion) inhibited the formation of nitorosomorpholine, but that brewed from $2.5 \mathrm{~g}$ and less (weak tea infusion) accelerated it as shown in Fig. 2. Next, we determined the concentration of catechins in each brewed tea infusion. The concentration in the green tea infusion brewed from $5 \mathrm{~g}$ leaves, which exhibited the inhibitory effect on the formation of nitrosomorpholine, was $684 \mathrm{mg} / \mathrm{l}$. However, the concentration in the green tea infusion brewed from 0.1, $0.5,1.0$ and $2.5 \mathrm{~g}$ tea leaves were $21,69,146$ and $307 \mathrm{mg} / \mathrm{l}$, respectively (Fig. 2).

We examined the formation of nitrosomorpholine in the solution containing (+)-catechin and nitrite at different molar ratios. In the solution in which the molar ratio of $(+)$-catechin to nirite was $0.025-0.1$, the amount of nitrosomorpholine formed was larger than in the solution without $(+)$-catechin (control), but in the solution in which the molar ratio was 0.15 and over, it was smaller than in the control (Fig. 3). Tanaka et al. reported that brewed green tea infusion and catechins had the strong inhibitory effect on the nitrosation of secondary amines in 

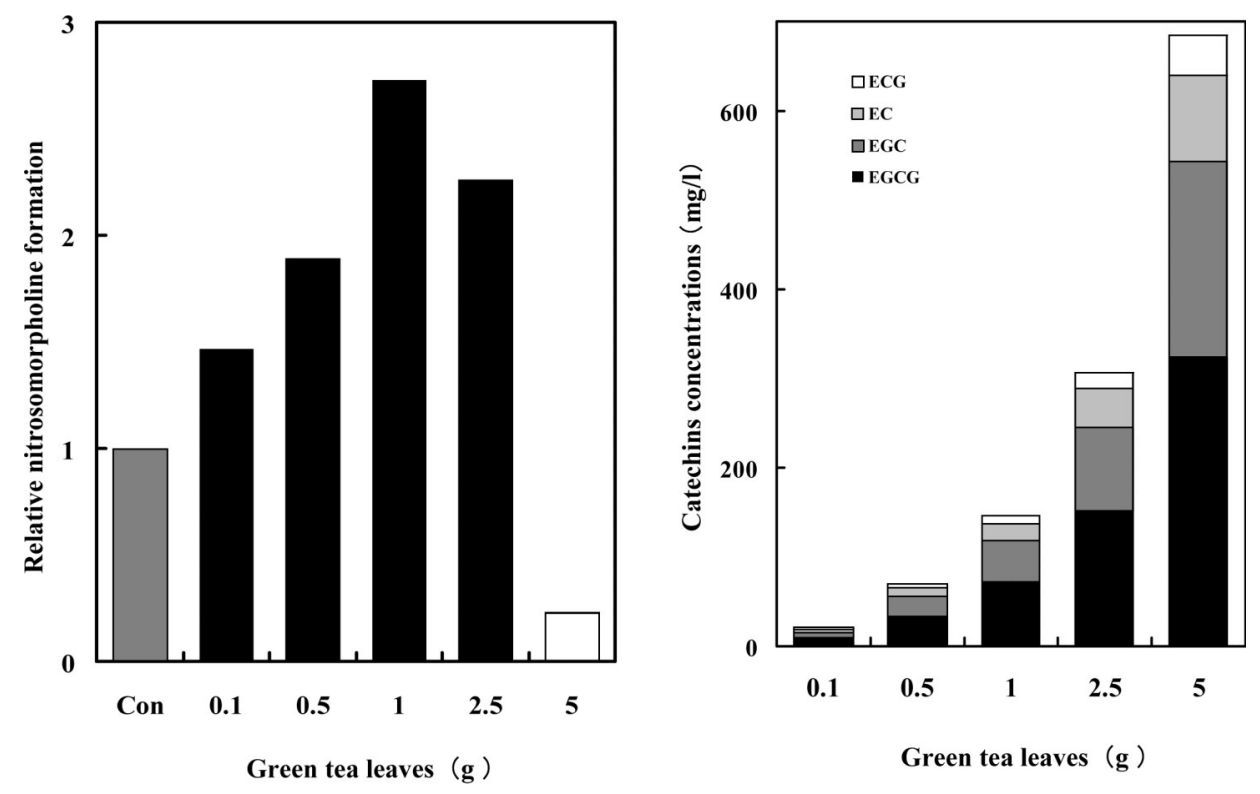

Fig. 2. Effect of the Weight of Green Tea Leaves on the Concentration of Catechins and the Formation of Nitrosomorpholinein the Brewed Green Tea

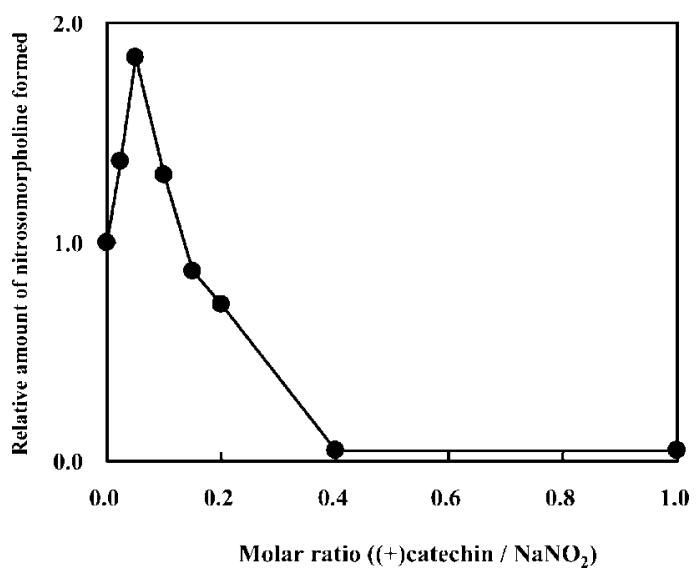

Fig. 3. Influence of Molar Ratio of (+)Catechin to Nitrite on the Formation of Nitrosomorpholine

vitro. ${ }^{14)}$ However, because they used only green tea infusion brewed at high concentrations, not at low concentrations, they did not observe the promoting effect of brewed tea infusion on the formation of nitrosamines. Nakamura and Kawabata reported both promoting and inhibitory effects of green tea infusion on nitrosamine formation in vitro, as was the case in our study. ${ }^{13)}$ They confirmed the existence of an optimum concentration of brewed green tea infusion for the catalytic effect on nitrosamine formation. Furthermore, they demonstrated that the nitrosation reaction could be inhibited by the presence of other polyphenols, such as flavonols, fla- vones and isoflavones.

From these results, we considered that the promoting and inhibitory effects of brewed green tea infusion on the formation of nitrosomorpholine might depend on the concentration of catechins in the brewed tea infusion and nitrite concentration, although we need to study the effects of chemicals contained in the brewed green tea infusion, such as vitamin $\mathrm{C}$, and tocopherol on the formation of nitrosamines.

We investigated the effects of eight moiety chemicals in catechins, such as resorcinol, phloroglucinol, catechol, pyrogallol, gallic acid, methyl gallate, phenol and hydroquinone, on the formation of nitrosomorpholine. Resorcinol and phloroglucinol, which have an A-ring model structure, accelerated the formation of nitrosomorpholine at a low concentration, and inhibited it at a high concentration (Fig. 4). However, other chemicals inhibited the nitrosation of morpholine dose-dependently, and did not show the same effect as (+)-catechin. Pignatelli et al. reported the catalytic action of catechins and resorcinol on the nitrosation of proline in vitro. ${ }^{27)} \mathrm{A}$ conceivable mechanism has been thought for the catalysis of nitrosation by some of phenolic compounds. C-nitroso derivatives may be formed by further reaction with the nitrosating species to generate a more powerful nitrosating agent, which could be a nitrosoquinone oxime derivative. Its reaction with the nitrosatable substrate produces the nitroso 


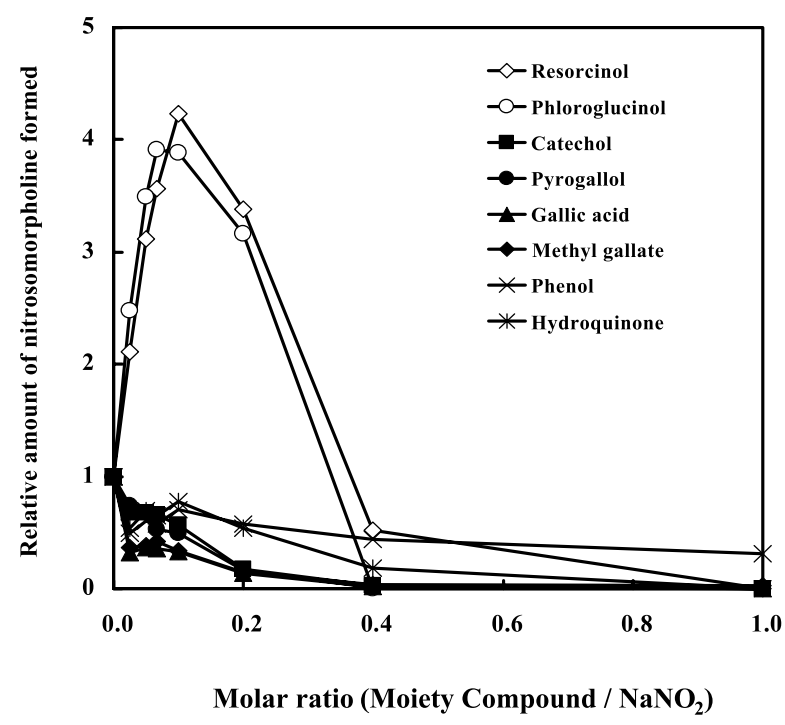<smiles>Oc1cccc(O)c1</smiles>

Resorcinol<smiles>Oc1cc(O)cc(O)c1</smiles>

Phloroglucinol

Fig. 4. Effect of Moiety Compounds of Catechins on the Formation of Nitrosomorpholine

compound. This mechanism indicates that increasing amounts of catalytically active phenolic compounds lead to higher concentrations of the C-nitroso intermediates, and consequently to a reduced concentration of the nitrosating species. This mechanism would explain the optimum ratio for nitrite to phenolic compound. Accordingly, a large excess of phenolic compound would inhibit nitrosation, because the nitrosating agent would be completely used up in forming the catalyst and none would be left to continue the catalytic reaction. Although we confirmed that the A-ring structure in catechins affected the formation of nitrosamines, the mechanism has not been clearly clarified yet. We need to examine the mechanism of catalytic and inhibitory activities of catechins on the nitrosation of secondary amines.

Next we examined the in vivo action of green tea on the formation of nitrosamines using Wistar male rats administered nitrite and morpholine. We found that the administration of $0.5,1.0$ and $2.0 \mathrm{mg} / \mathrm{kg}$ of freeze-dried brewed green tea extract increased the production of nitrosomorpholine in the stomach as compared with the control group (Fig. 5). Especially the administration of $1.0 \mathrm{mg} / \mathrm{kg}$ body weight of green tea extract significantly (2.3-fold) increased the formation of nitorosomorpholine in the stomach (Fig. 5). However, the administration of green tea extract at a dose of 5.0 or $10.0 \mathrm{mg} / \mathrm{kg}$ body weight significantly inhibited the formation of nitorosomorpholine in the stomach (Fig. 5). It is said that Japanese usually intakes $190.8 \pm 128.3 \mathrm{mg} /$ day of nitrate and $3.837 \pm 3.647 \mathrm{mg} /$ day of nitrite. While,

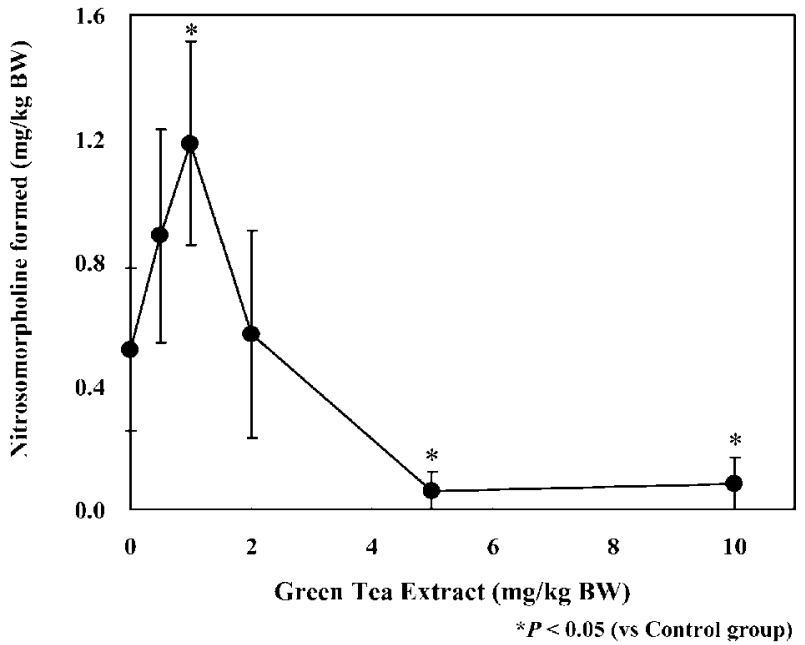

Fig. 5. Effect of Brewed Green Tea on the Formation of Nitrosomorpholine in Rats

Freeze-dried brewed green tea was administered by gastric intubation. At the same time, the water solution of sodium nitrite and morpholine were administered at a dose of 40 and $20 \mu \mathrm{mol} / \mathrm{kg}$ body weight, respectively. After administration of them, stomachs were cut out and treated with dichloromethane. The extracts were analyzed for nitrosomorpholine concentration by GC/MS.

nitrate are contained on the high concentrations in spinach, chinese cabbage and mushroom, respectively $(3560 \pm 552,1040 \pm 289,1836 \pm 48 \mu \mathrm{g} / \mathrm{g})$. Dental bacteria in mouth or the storage of vegetables easily reduces nitrate to nitrite. There is an example that adults got food poisoning by eating spinach contained high concentration nitrate. Therefore, we thought that the concentration of nitrite administered to rats in this experiments was reflected the human 


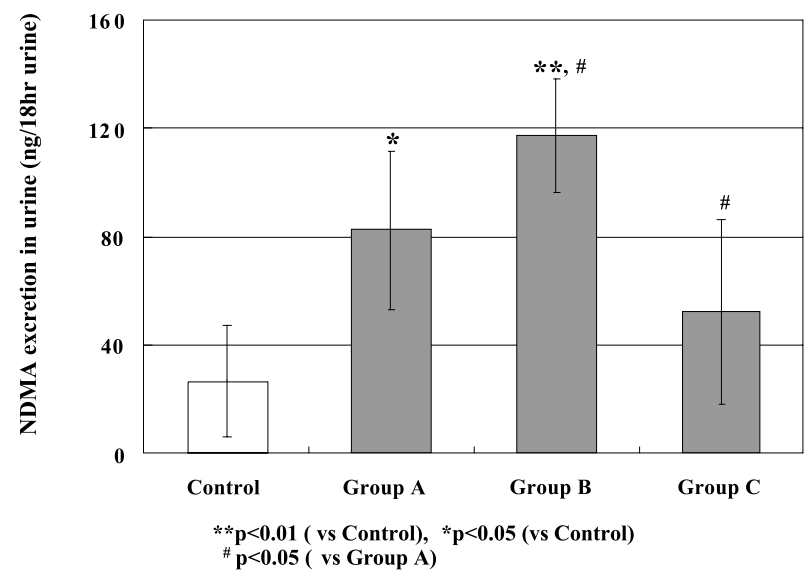

Fig. 6. Nitrosodimethylamine (NDMA) Excreted in Human Urine before and after Ingestion of Test Diet

Group A; did not drink green tea, Group B; consumed green tea at a low concentration ( $30 \mathrm{mg}$ catechins/200 ml), Group C; consumed green tea at a high concentration $(300 \mathrm{mg}$ catechins/200 ml). The urine samples were collected for $18 \mathrm{hr}$ after the experimental diets were consumed. Each sample was extracted with dichloromethane, analyzed for nitrosodimethylamine concentration by GC/MS

intake of nitrite. Pignatelli et al. determined the concentration of nitrosoproline in $24 \mathrm{hr}$ urine excreted from the rats administered nitrite, proline and catechin. ${ }^{27)}$ They reported that the catalytic and inhibitory effects of catechin on the nitrosation of proline in rats depended on the concentration of catechin. Thus, the effects of brewed green tea infusion in vitro and in vivo were opposite on the nitrosation of secondary amines

There are few reports about these opposite effects of brewed green tea infusion on the formation of nitrosamines in humans. Therefore, we examined the effects of brewed green tea infusion on the endogenous formation of nitrosoamines in human subjects taking the experimental meal rich in nitrate and dimethylamine. The concentration of nitrosodimethylamine on control days (not taking the experimental meal) was $26.7 \pm 20.1 \mathrm{ng} / 18 \mathrm{hr}$ urine as shown in Fig. 6. In the group consuming the experimental meals rich in nitrite and dimethylamine but without brewed green tea infusion (group A), the concentration of nitrosodimethylamine in $18 \mathrm{hr}$ urine was $82.2 \pm 29.6 \mathrm{ng}$, which was significantly higher than that on the control days (Fig. 6). In the group consuming green tea infusion brewed at a low concentration (weak tea infusion; group B) the concentration of nitrosodimethylamine was $117.4 \pm 20.9$ $\mathrm{ng} / 18 \mathrm{hr}$ urine, which was significantly higher that that in group A (Fig. 6). In the group consuming green tea infusion brewed at a high concentration (group C), the concentration of nitrosodimethylamine in urine was significantly lower (52.2 \pm $34.0 \mathrm{ng} / 18 \mathrm{hr}$ urine) than that in group A (Fig. 6). Thus, in tests with rats and human also, brewed green tea infusion exhibited the contradictory effect (promoting and inhibitory) on the formation of nitrosoamines depending on the concentration of green tea infusion as in rats and in vitro experiment. There are some reports about the inhibitory effect of brewed green tea infusion on the nitrosation of secondary amines in vivo. Coi et al. showed that the excretion amount of nitrosamines in urine was significantly decreased by administration of brewed green tea infusion in human taking secondary amines and nitrate-rich foods. ${ }^{28)}$ Vermeer et al. reported that consumption of four cups of green tea infusion $(2 \mathrm{~g})$ per day significantly decreased the amount of nitrosodimethylamine in the urine of humans who consumed a meal of fish rich in amines and nitratecontaining drinking water. ${ }^{29)}$ Consumption of eight cups of green tea infusion ( $4 \mathrm{~g}$ ) per day, however, significantly increased nitrosodimethylamine excretion. They reasoned that this increase is probably a result of catalytic effects of tea polyphenol on nitrosation. Consequently, we assume that there is an optimal amount of green tea against nitrite amount for inhibition of the formation of nitrosamines. We recommend that we take in higher concentration of green tea infusion to protect from nitrosamines formation in stomach, because it is impossible to detect the contained level of nitrate and nitrite in foodstuffs during a meal.

In the following experiments, we determined the concentration of catechins in green tea infusion brewed by the general households in seven tea-producing areas and seven non-tea-producing areas (Fig. 7). The concentration of catechins in the brewed green tea infusion in tea-producing areas tended to be higher than that in non-producing areas. The green tea infusion brewed in area I contained larger amount of catechins $(717 \pm 336 \mathrm{mg} / \mathrm{l})$ than that in other areas. In contrast, the green tea infusion brewed in area $\mathrm{C}$ contained a smaller amount of catechins than in other areas. The mean catechin concentration in the green tea infusion brewed in tea-producing areas was $569 \pm 259 \mathrm{mg} / \mathrm{l}$, and was significantly higher than that in non-producing area $(418 \pm 224 \mathrm{mg} / \mathrm{l})$ as shown in Fig. 7. We examined the relationship between catechin concentration in green tea infusion brewed in each area and the SMR of stomach, lung and colon cancers in respective area. The SMR was significantly correlated with the concentration of cat- 


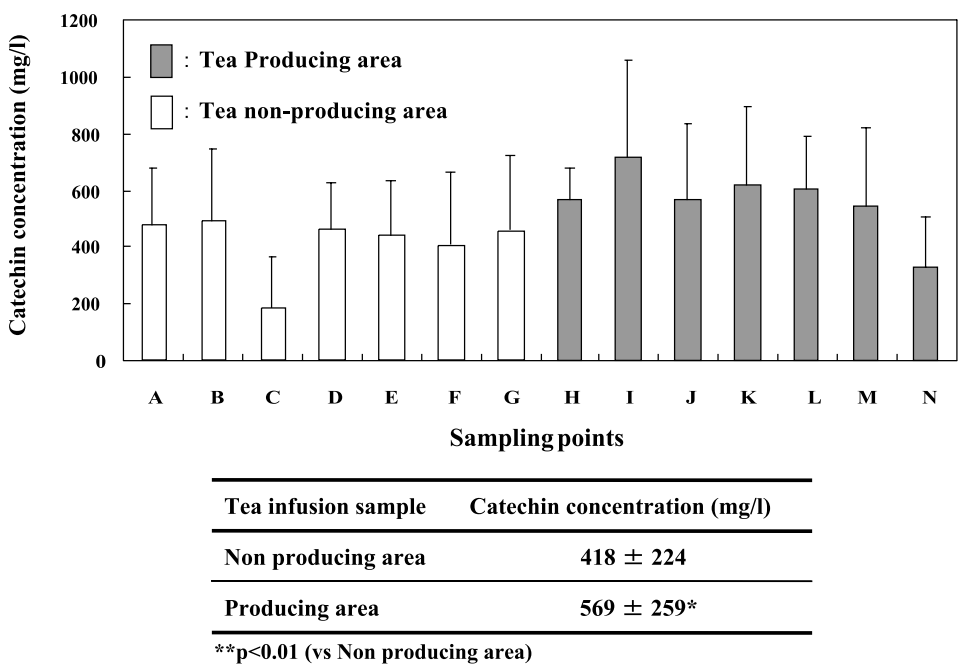

Fig. 7. Comparison of Catechin Concentrations in Green Tea Brewed by Households in Tea-Producing Areas and Non-Producing Areas in Japan
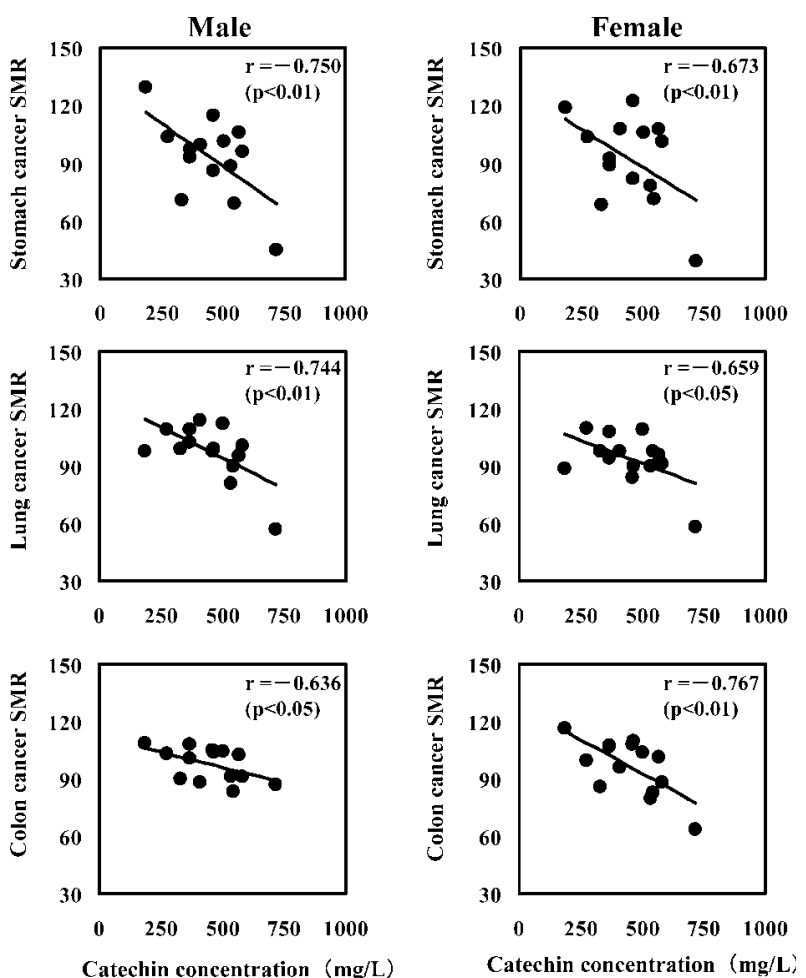

Fig. 8. Relationship between Catechin Concentration in the Brewed Green Tea and Cancer SMR in 14 Areas (19951999)

echins in brewed green tea (Fig. 8). These results show that drinking green tea infusion brewed at a high concentration (strong tea infusion) might decrease the risk of dying of cancer. Oguni et al. reported that SMR of cancer was very low in the green tea-producing areas and people in such areas drank lots of brewed green tea infusion based on an ecological study. ${ }^{16)}$ Some previous case studies showed that the risk of gastric cancer was reduced by increased consumption of brewed green tea infusion. Inoue et al. demonstrated that the rate of suffering from stomach cancer was significantly decreased by increasing the intake of green tea infusion ( 7 cups or more per day) in case studies. ${ }^{18)}$ Gao et al. also observed an inverse correlation between the amount of tea infusion drinking and endometrial cancer risk, and reported that regular tea drinkers had a reduced risk of endometrial cancer in premenopausal women compared with non-tea drinkers in case studies. ${ }^{21)}$

Some researchers, however, found that drinking green tea infusion is not related with cancer prevention in a prospective cohort study. It is thought that using the prospective cohort study gives more strict results than case-control studies and the ecological studies. Suzuki et al. reported that consumption of green tea infusion ( 5 cups or more per day) was not associated with a lower risk of colorectal and breast cancers using the prospective cohort study. ${ }^{30,31)}$ Tsubono et al. reported the same results on gastric cancer. ${ }^{22)}$ However, Sasazuki et al. recently observed that an inverse correlation between green tea infusion consumption ( 5 or more cups per day) and distal gastric cancer was observed among women recently. ${ }^{32)}$ As mentioned above, there are some reports about contradictory effects of green tea on the risk of cancer using epidemiological researches. These studies, however, examined only the number of cups 
taken per day, and not the catechin concentration in each cup of brewed tea infusion taken by the subjects.

However, we examined the concentrations of catechins in green tea infusion brewed by the general households in different areas and found differences in the concentration of catechin between the tea infusions brewed in green tea-producing and nonproducing areas, and among those brewed by households in the same sampling area. The results showed that the concentration of catechins in brewed green tea infusion might be very important factor in the epidemiological study on the relationship between green tea infusion consumption and the risk of cancer. However, we determined only fifteen-twenty tea infusion samples from one area. Therefore, we need to collect many more green tea infusion samples from one area, and detect catechins concentration in a cup of green tea infusion in future. In addition, we have to examine how to brew green tea infusion in each family in sampling areas, because brewed methods were different among all families.

In this study, we demonstrated that the formation of nitrosoamines was inhibited by green tea with a high catechin concentration, but was accelerated by that with a low concentration. Furthermore, an inverse relationship was observed between catechin concentration in brewed green tea infusion consumed by humans and SMR of cancer. From these results, we recommend discarding green tea leaves after the second brewing and using lots of tea leaves. However, we need to examine further the effect of green tea infusion consumption on the risk of cancer using more detailed data, such as catechin concentration in brewed green tea infusion or amount of brewed green tea infusion consumed by humans.

\section{REFERENCES}

1) Feron, V. J., Cassee, F. R., Groten, J. P., van Vliet, P. W. and van Zorge, J. A. (2002) International issues on human health effects of exposure to chemical mixtures. Environ. Health Perspect., 110, 893-899.

2) Goldman, R. and Shields, P. G. (2003) Food mutagens. J. Nutr., 133, 965S-973S.

3) Groves, F. D., Issaq, H., Fox, S., Jeffrey, A. M., Whysner, J., Zhang, L., You, W. C. and Fraumeni, J. F., Jr. (2002) N-nitroso compounds and mutagens in Chinese fermented (sour) corn pancakes. J.AOAC Int., 85, 1052-1056.

4) Aiub, C. A., Pinto, L. F. and Felzenszwalb, I. (2003)
N-Nitrosodiethylamine mutagenicity at low concentrations. Toxicol. Lett., 145, 36-45.

5) Erba, D., Riso, P., Bordoni, A., Foti, P., Biagi, P. L. and Testolin, G. (2005) Effectiveness of moderate green tea consumption on antioxidative status and plasma lipid profile in humans. J. Nutr. Biochem., 16, 144-149.

6) Joshi, S., Hasan, S. K., Chandra, R., Husain, M. M. and Srivastava, R. C. (2004) Scavenging action of zinc and green tea polyphenol on cisplatin and nickel induced nitric oxide generation and lipid peroxidation in rats. Biomed. Environ. Sci., 17, 402409.

7) Yamamoto, Y., Matsunaga, K. and Friedman, H. (2004) Protective effects of green tea catechins on alveolar macrophages against bacterial infections. Biofactors, 21, 119-21.

8) Bunkova, R., Marova, I. and Nemec, M. (2005) Antimutagenic properties of green tea. Plant Foods Hum. Nutr., 60, 25-29.

9) Ohata, M., Koyama, Y., Suzuki, T., Hayakawa, S., Saeki, K., Nakamura, Y. and Isemura, M. (2005) Effects of tea constituents on cell cycle progression of human leukemia U937 cells. Biomed. Res., 26, 1-7.

10) Weitberg, A. B. and Corvese, D. (1999) The effect of epigallocatechin galleate and sarcophytol A on DNA strand breakage induced by tobacco-specific nitrosamines and stimulated human phagocytes. $J$. Exp. Clin. Cancer Res., 18, 433-437.

11) Crespy, V. and Williamson, G. (2004) A review of the health effects of green tea catechins in in vivo animal models. J. Nutr., 134, 3431S-3440S.

12) Sasazuki, S., Kodama, H., Yoshimasu, K., Liu, Y., Washio, M., Tanaka, K., Tokunaga, S., Kono, S., Arai, H., Doi, Y., Kawano, T., Nakagaki, O., Takada, K., Koyanagi, S., Hiyamuta, K., Nii, T., Shirai, K., Ideishi, M., Arakawa, K., Mohri, M. and Takeshita, A. (2000) Relation between green tea consumption and the severity of coronary atherosclerosis among Japanese men and women. Ann. Epidemiol., 10, 401408.

13) Nakamura, M. and Kawabata, T. (1981) Effect of Japanese green tea on nitrosamine formation in vitro. J. Food Science, 46, 306-307.

14) Tanaka, K., Hayatsu, T., Negishi, T. and Hayatsu, H. (1998) Inhibition of N-nitrosation of secondary amines in vitro by tea extracts and catechins. Mutat. Res., 412, 91-98.

15) Truong, M. P., Fujino, Y., Yoshimura, T., Tokui. N., Mizoue, T., Yatsuya, H., Toyoshima, H., Sakata, K., Kikuchi, S., Hoshiyama, Y., Kubo, T., Tamakoshi, A. and JACC Study Group (2005) Mortality and incidence rates of stomach cancer in the JACC Study. J. Epidemiol., 15, S89-S97. 
16) Oguni, I., Nasu, K., Ota, Y., Yamamoto, S. and Nomura, T. (1989) Epidemiological and experimental studies on the antitumor activity by green tea extracts. Jpn. J .Nutr., 47, 93-102.

17) Ji, B. T., Chow, W. H., Yang, G., McLaughlin, J. K., Gao, R. N., Zheng, W., Shu, X. O., Jin, F., Fraumeni, J. F., Jr. and Gao, Y. T. (1996) The influence of cigarette smoking, alcohol, and green tea consumption on the risk of carcinoma of the cardia and distal stomach in Shanghai, China. Cancer, 77, 2449-2457.

18) Inoue, M., Tajima, K., Hirose, K., Hamajima, N., Takezaki, T., Kuroishi, T. and Tominaga, S. (1998) Tea and coffee consumption and the risk of digestive tract cancers: data from a comparative case-referent study in Japan. Cancer Causes Control, 9, 209216.

19) Hoshiyama, Y., Kawaguchi, T., Miura, Y., Mizoue, T., Tokui, N., Yatsuya, H., Sakata, K., Kondo, T., Kikuchi, S., Toyoshima, H., Hayakawa, N., Tamakoshi, A., Ohno, Y. and Yoshimura, T. (2004) Japan Collaborative Cohort Study Group., A nested case-control study of stomach cancer in relation to green tea consumption in Japan. Br. J. Cancer, 90, 135-138.

20) Mu, L. N., Lu, Q. Y., Yu, S. Z., Jiang, Q. W., Cao, W., You, N. C., Setiawan, V. W., Zhou, X. F., Ding, B. G., Wang, R. H., Zhao, J., Cai, L., Rao, J. Y., Heber, D. and Zhang, Z. F. (2005) Green tea drinking and multigenetic index on the risk of stomach cancer in a Chinese population. Int. J. Cancer., 116, 972-983.

21) Gao, J., Xiang, Y. B., Xu, W. H., Shao, C. X., Ruan, Z. X., Cheng, J. R., Shu, X. O. and Gao, Y. T. (2005) Green tea consumption and the risk of endometrial cancer: a population-based case-control study in urban Shanghai. Zhonghua Liu Xing Bing Xue Za Zhi, 26, 323-327.

22) Tsubono, Y., Nishino, Y., Komatsu, S., Hsieh, C. C., Kanemura, S., Tsuji, I., Nakatsuka, H., Fukao, A., Satoh, H. and Hisamichi, S. (2001) Green tea and the risk of gastric cancer in Japan. N. Engl. J. Med., 344, 632-636.

23) Nagano, J., Kono, S., Preston, D. L. and Mabuchi, K. (2001) A prospective study of green tea consumption and cancer incidence, Hiroshima and Nagasaki (Japan). Cancer Causes Control., 12, 501-508.

24) Koizumi, Y., Tsubono, Y., Nakaya, N., Nishino, Y., Shibuya, D., Matsuoka, H. and Tsuji, I. (2003) No association between green tea and the risk of gastric cancer: pooled analysis of two prospective studies in Japan. Cancer Epidemiol. Biomarkers Prev., 12, 472-473.

25) Hoshiyama, Y., Kawaguchi, T., Miura, Y., Mizoue, T., Tokui, N., Yatsuya, H., Sakata, K., Kondo, T., Kikuchi, S., Toyoshima, H., Hayakawa, N., Tamakoshi, A., Yoshimura, T. and JACC Study Group (2005) Green tea and stomach cancer - a short review of prospective studies. J. Epidemiol., 15, S109-S112.

26) Groenen, P. J., de Cock-Bethbeder, M. W., Bouwman, J. and Dhont, J. H. (1980) Formation of $\mathrm{N}$-nitrosamine and $\mathrm{N}$-nitrosamino acids from food products and nitrite under simulated gastric conditions. IARC Sci. Publ., 31, 215-229.

27) Pignatelli, B., Bereziat, J. C., Descotes, G. and Bartsch, H. (1982) Catalysis of nitrosation in vitro and in vivo in rats by catechin and resorcinol and inhibition by chlorogenic acid. Carcinogenesis, $\mathbf{3}$, 1045-1049.

28) Choi, S. Y., Chung, M. J. and Sung, N. J. (2002) Volatile N-nitrosamine inhibition after intake Korean green tea and Maesil (Prunus mume SIEB. et ZACC.) extracts with an amine-rich diet in subjects ingesting nitrate. Food Chem. Toxicol., 40, 949-957.

29) Vermeer, I. T., Moonen, E. J., Dallinga, J. W., Kleinjans, J. C. and van Maanen, J. M. (1999) Effect of ascorbic acid and green tea on endogenous formation of $\mathrm{N}$-nitrosodimethylamine and $\mathrm{N}$ nitrosopiperidine in humans. Mutat. Res., 428, 353361.

30) Suzuki, Y., Tsubono, Y., Nakaya, N., Suzuki, Y., Koizumi, Y. and Tsuji, I. (2004) Green tea and the risk of breast cancer: pooled analysis of two prospective studies in Japan. Br. J. Cancer., 90, 13611363.

31) Suzuki, Y., Tsubono, Y., Nakaya, N., Koizumi, Y., Suzuki, Y., Shibuya, D. and Tsuji, I. (2005) Green tea and the risk of colorectal cancer: pooled analysis of two prospective studies in Japan. J. Epidemiol., 15, 118-124.

32) Sasazuki, S., Inoue, M., Hanaoka, T., Yamamoto, S., Sobue, T. and Tsugane, S. (2004) Green tea consumption and subsequent risk of gastric cancer by subsite: the JPHC Study. Cancer Causes Control., 15, 483-491. 